\title{
Endotoxemia in the Rhesus Monkey: Alterations in Host Lipid and Carbohydrate Metabolism
}

\author{
R. H. FISER ${ }^{[28]}$ \\ Department of Pediatrics, Harbor General Hospital, Torrance, California, USA \\ J. C. Denniston \\ Department of Physiology, Baylor College of Medicine, Houston, Texas, USA
}

W. R. BEISEL

United States Army Medical Research Institute of Infectious Diseases, Frederick, Maryland, USA

\section{Extract}

Experimentally induced endotoxemia in the rhesus monkey produced a two- to fourfold increase in plasma triglyceride concentration; glucose administration partially prevented this rise. Plasma free fatty acid and phospholipid values were depressed 40$50 \%$ of control values whereas cholesterol values were unchanged. Endotoxin-treated monkeys displayed slowed glucose disappearance ( $\mathrm{K}$ values, 2.2 versus 1.1 ) and higher levels of sugar in blood when given glucose $(72 \pm 8 \mathrm{mg} / 100 \mathrm{ml}$ versus $151 \pm 11 \mathrm{mg} /$ $100 \mathrm{ml}$ ). These studies indicate that endotoxin has a marked effect on the pattern of substrate utilization by the host.

\section{Speculation}

Alterations in lipid and carbohydrate metabolism affecting substrate utilization of the host may account for many of the clinicopathologic events associated with endotoxemia. Therapeutic measures designed to increase the availability of metabolic fuels for efficient cellular fuel utilization might be of value to patients during endotoxemia.

\section{Introduction}

Gram-negative sepsis is associated with marked derangements in lipid and carbohydrate metabolism in man $[9,15,16,20]$ and experimental animals [6]. A recent study [15] suggested that endotoxin, which circulates during gram-negative sepsis, was responsible for many physiologic alterations. To assess certain of these changes in a prospective manner, we have studied the sequential response of host lipid and carbohydrate metabolism during experimentally induced endotoxemia in the rhesus monkey.

\section{Materials and Methods}

Twenty-four healthy monkeys which weighed $3-4 \mathrm{~kg}$ were maintained on a commercial diet [22] for a minimum of 4 months under optimal animal colony conditions and then held 1 week in individual restraint chairs. Monkeys were studied in four groups of six, with each monkey that received endotoxin being matched with a sham-inoculated control of similar weight and sex.

Femoral arterial and venous catheters were inserted $36 \mathrm{hr}$ before study; monkeys then were allowed only 


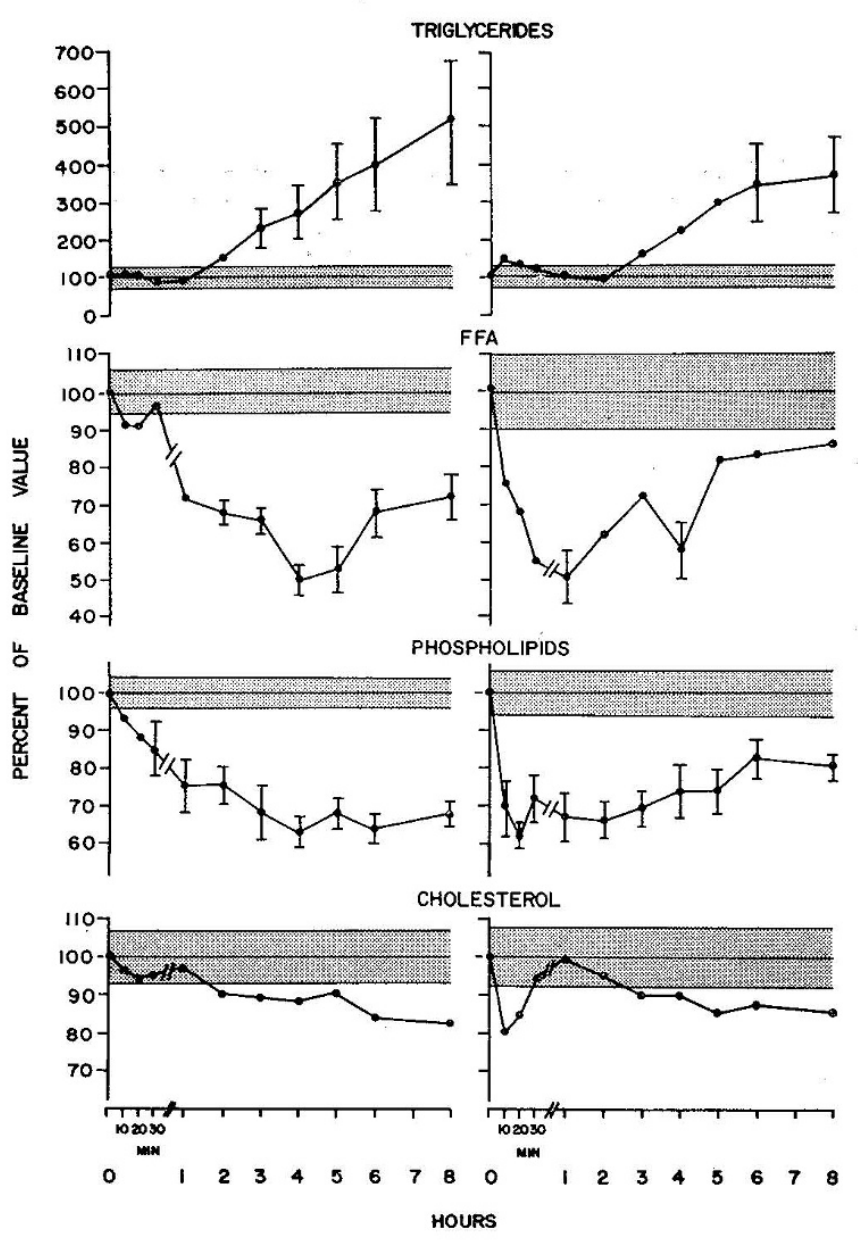

Fig. 1. Sequential changes in plasma lipid concentrations of endotoxin-treated monkeys without (left) and with (right) glucose present. Data represent the mean \pm sEM values of six monkeys in each group; points with SEM values indicate significant $(P<$ 0.05 ) change from base-line values of each group as determined by paired $t$ tests; horizontal shaded bands represent the mean \pm SEM of control values. All monkeys were fasted for $36 \mathrm{hr}$ before the study; groups plotted on the right were given a bolus intravenous injection of glucose at zero time. Mean \pm SEM absolute base-line lipid values: triglycerides $29 \pm 3 \mathrm{mg} / 100 \mathrm{ml}$, free fatty acids $(F F A) 32 \pm 3 \mathrm{mg} / 100 \mathrm{ml}$, phospholipids $716 \pm 32 \mathrm{mg} / 100$ $\mathrm{mI}$, and cholesterol $122 \pm 3 \mathrm{mg} / 100 \mathrm{ml}$.

water until studied. After blood was obtained for baseline laboratory values, monkeys in two of the four groups were given an intravenous bolus injection of $1.5 \mathrm{~g} / \mathrm{kg}$ glucose as a $50 \%$ solution in water. This was followed immediately by either $5 \mathrm{mg} / \mathrm{kg}$ Salmonella typhimurium endotoxin [23], or, in control groups, by $5 \mathrm{mg} / \mathrm{kg} 5 \%$ human serum albumin in $0.9 \%$ sodium chloride; the four groups thus included endotoxemic and control monkeys which were either glucose loaded or fasted. Blood was sampled at 30 -min intervals for
$7 \mathrm{hr}$. Samples were treated with EDTA and their plasma separated by centrifugation at $4^{\circ}$. Total and differential whole blood counts and serum glutamic oxaloacetic transaminase [24] were measured serially. Body temperature was measured by indwelling rectal probes and blood pressure by a transducer connected to the arterial catheter [25].

Major plasma lipid classes and plasma glucose were assayed by automated techniques [2, 18]. Plasma lipoprotein concentrations were determined by the method of Farber et al. [5]. Plasma insulin was determined by a coated charcoal radioimmunoassay method [11].

Gross and microscopic pathologic studies were conducted on monkeys that died. Student's $t$ test was used to compare control and experimental test values of each group.

\section{Results}

A febrile response was noted within $1 \mathrm{hr}$ or less after the intravenous injection of endotoxin in all experimental monkeys and reached a peak at $4 \mathrm{hr}$. Hypothermia often developed before death. During endotoxemia, monkeys exhibited polydipsia and lethargy and in many instances manifested progressive stupor, tachypnea, tachycardia, and deepening shock. Five of the six monkeys given glucose died between 10 and 16 hr after endotoxin. Death occurred in three of the six fasted endotoxemia monkeys at 2,8 , and $27 \mathrm{hr}$ postchallenge. No clinical differences were noted between the glucose-loaded or fasted endotoxemic groups.

Leukopenia developed within 10 min after endotoxin and persisted throughout the study with nadir values between 4-6 hr. The serum glutamic oxaloacetic transaminase values became slightly elevated in all monkeys that died. Control monkeys exhibited no hematologic or biochemical changes.

Figure 1 presents triglyceride, free fatty acid, phospholipid, and total cholesterol values for each group of monkeys plotted as percentage of control values. Probability, $P$ values, were determined by comparing postchallenge values with control values from the same monkeys using paired $t$ tests. Tables I and II present the actual values in both fasted and glucose-infused monkeys after endotoxin or sham injections.

During endotoxemia, triglyceride values increased in both the glucose-loaded and fasted monkeys (Fig. $1)$, with individual values showing two to fourfold increase by $7 \mathrm{hr}$. In the fasted endotoxemic monkeys, triglyceride concentrations were significantly increased above base-line control values by $2 \mathrm{hr}$ and remained 
Table I. Plasma lipid values in fasted monkeys ${ }^{1}$

\begin{tabular}{|c|c|c|c|c|c|c|c|c|}
\hline \multirow{2}{*}{ Lipid, mg/100 ml } & \multicolumn{8}{|c|}{ Time, hr } \\
\hline & 0 & 1 & 2 & 3 & 4 & 5 & 6 & 7 \\
\hline \multicolumn{9}{|l|}{ Control } \\
\hline Triglyceride & $43 \pm 9$ & $49 \pm 4$ & $53 \pm 8$ & $54 \pm 9$ & $55 \pm 12$ & $58 \pm 13$ & $62 \pm 12$ & $57 \pm 12$ \\
\hline Free fatty acid & $36 \pm 10$ & $29 \pm 5$ & $28 \pm 5$ & $26 \pm 5$ & $23 \pm 2$ & $22 \pm 2$ & $24 \pm 3$ & $22 \pm 2$ \\
\hline Phospholipid & $683 \pm 57$ & $618 \pm 90$ & $577 \pm 70$ & $550 \pm 61$ & $557 \pm 67$ & $605 \pm 67$ & $602 \pm 66$ & $560 \pm 63$ \\
\hline Cholesterol & $126 \pm 9$ & $125 \pm 9$ & $125 \pm 10$ & $119 \pm 8$ & $116 \pm 9$ & $121 \pm 8$ & $118 \pm 7$ & $114 \pm 8$ \\
\hline \multicolumn{9}{|l|}{ Endotoxin } \\
\hline Triglyceride & $33 \pm 3$ & $30 \pm 6$ & $46 \pm 6$ & $69 \pm 14$ & $82 \pm 21$ & $106 \pm 32$ & $119 \pm 36$ & $152 \pm 50$ \\
\hline Free fatty acid & $32 \pm 2$ & $23 \pm 3$ & $22 \pm 1$ & $21 \pm 1$ & $16 \pm 1$ & $17 \pm 2$ & $21 \pm 2$ & $22 \pm 2$ \\
\hline Phospholipid & $830 \pm 30$ & $622 \pm b 3$ & $626 \pm 42$ & $564 \pm 51$ & $512 \pm 28$ & $548 \pm 26$ & $524 \pm 25$ & $573 \pm 14$ \\
\hline Cholesterol & $116 \pm 8$ & $112 \pm 9$ & $105 \pm 8$ & $104 \pm 10$ & $103 \pm 10$ & $104 \pm 11$ & $98 \pm 10$ & $97 \pm 14$ \\
\hline
\end{tabular}

Values represent the mean \pm SEM of six monkeys in each group.

Table II. Plasma lipid values in monkeys given glucose, $1.5 \mathrm{~g} / \mathrm{Kg}^{1}$

\begin{tabular}{|c|c|c|c|c|c|c|c|c|}
\hline \multirow{2}{*}{ Lipid, mg/100 nl } & \multicolumn{8}{|c|}{ ¡Time, hr } \\
\hline & 0 & 1 & 2 & 3 & 4 & 5 & 6 & 7 \\
\hline \multicolumn{9}{|l|}{ Control } \\
\hline Triglyceride & $22 \pm 3$ & $23 \pm 4$ & $25 \pm 3$ & $21 \pm 4$ & $19 \pm 3$ & $20 \pm 3$ & $23 \pm 4$ & $21 \pm 3$ \\
\hline Free fatty acid & $26 \pm 2$ & $10 \pm 2$ & $14 \pm 4$ & $22 \pm 4$ & $21 \pm 1$ & $28 \pm 5$ & $21 \pm 3$ & $19 \pm 2$ \\
\hline Phospholipid & $848 \pm 97$ & $432 \pm 32$ & $426 \pm 37$ & $592 \pm 58$ & $628 \pm 50$ & $712 \pm 80$ & $674 \pm 89$ & $600 \pm 70$ \\
\hline Cholesterol & $131 \pm 12$ & $128 \pm 14$ & $131 \pm 14$ & $119 \pm 12$ & $114 \pm 12$ & $116 \pm 11$ & $126 \pm 14$ & $122 \pm 14$ \\
\hline \multicolumn{9}{|l|}{ Endotoxin } \\
\hline Triglyceride & $18 \pm 5$ & $21 \pm 4$ & $26 \pm 4$ & $33 \pm 8$ & $43 \pm 12$ & $54 \pm 15$ & $70 \pm 20$ & $75 \pm 24$ \\
\hline Free fatty acid & $29 \pm 3$ & $15 \pm 2$ & $18 \pm 2$ & $20 \pm 3$ & $18 \pm 2$ & $24 \pm 3$ & $24 \pm 3$ & $24 \pm 3$ \\
\hline Phospholipid & $591 \pm 31$ & $392 \pm 31$ & $403 \pm 31$ & $422 \pm 34$ & $416 \pm 29$ & $427 \pm 37$ & $421 \leq 27$ & $476 \pm 22$ \\
\hline Cholesterol & $120 \pm 10$ & $119 \pm \delta$ & $114 \pm 10$ & $111 \pm 10$ & $107 \pm 9$ & $103 \pm 10$ & $105 \pm 8$ & $101 \pm 9$ \\
\hline
\end{tabular}

${ }^{1}$ Values represent the mean \pm SEM of six monkeys in each group.

high thereafter. These endotoxin-related changes tended to be less marked $(P<0.05)$ in the monkeys that had been given intravenous glucose. Triglyceride values of control monkeys were essentially stable throughout.

Free fatty acid values did not change significantly in fasted control monkeys. In contrast, values in fasted endotoxemic monkeys were significantly depressed by $2 \mathrm{hr}$, continued to decline over the next 4 hr, and then returned toward base line (Fig. 1), but continued to be significantly depressed. Free fatty acid values in both the control and endotoxemic monkeys were initially depressed after the glucose load and in both groups thereafter showed a gradual return toward base line by $7 \mathrm{hr}$.

Although fasted control monkeys showed no statistical change in phospholipids, these values were depressed below base line during endotoxemia in both fasted and glucose-loaded monkeys; values tended to rebound toward base line by $3 \mathrm{hr}$ in the monkeys given glucose.
Cholesterol values in both control and endotoxemic monkeys showed early, slight transient decline in cholesterol. However, these changes were not statistically significant.

Very low density lipoprotein concentrations determined on cellulose acetate showed small increases which tended to parallel the rise in serum triglycerides.

In contrast to the control group given glucose, plasma glucose concentrations at $4 \mathrm{hr}$ were increased two- to threefold in monkeys given glucose and endotoxin $(72 \pm 8 \mathrm{mg} / 100 \mathrm{ml}$ versus $151 \pm 11 \mathrm{mg} / 100 \mathrm{ml}$, $P<0.001)$. Although glucose was administered at the same time as endotoxin, the calculated mean $\mathrm{K}$ value of 1.1 for glucose disappearance was less than half of that measured in normal nontoxic controls. Glucose values in fasted monkeys given endotoxin remained relatively stable. After glucose administration, serum insulin values in endotoxemic monkeys were increased two- to threefold over base-line values, but increases were not greater than in controls.

No correlation was noted in any biochemical or 
hematologic parameters measured that could serve as an index of the severity of the effects or eventual demise of these monkeys.

\section{Discussion}

Metabolic fuel alterations due solely to endotoxin have been difficult to assess in patients with gramnegative sepsis because of the overlap between bacteremia and endotoxemia. The present data document important alterations in carbohydrate and lipid metabolism during endotoxemia. Hyperglycemia was evident within $2 \mathrm{hr}$ and slowed utilization of glucose was observed in endotoxic monkeys given glucose. A similar tendency to hyperglycemia has been reported due to Escherichia coli sepsis in baboons [4]. Relative hyperglycemia also was described by Lees et al. [14] in young adults during an experimental viral infection and has been reported in mice infected with encephalomyocarditis virus [3]. An absolute or relative insulin lack, possibly related to catecholamine excess, has been suggested to explain these findings [4]. Insulin resistance due either to free fatty acid increases [14] or increased secretion of pancreatic glucagon [17, 19] could also contribute to the elevated glucose concentrations. In contrast to these results, Yeung described significant hypoglycemia during gram sepsis in neonates [20] and postulated increased glucose utilization as a possible cause [21].

Levin et al. [15] have attributed many of the alterations in serum lipids noted during gram-negative sepsis to the presence of circulating endotoxin. Several patients in that study manifested hypertriglyceridemia but only a few showed elevations of free fatty acids. In contrast, Gallin et al. [9] detected increases of both free fatty acids and triglycerides in the serum of patients with gram negative sepsis, whereas Pollack et al. [16] reported depressed total serum lipids in children during gram-negative sepsis. In an attempt to explain these alterations of triglyceride levels, the dynamic aspects of triglyceride metabolism during endotoxemia and the influence of acute intravenous glucose on triglyceride responses must be considered; endotoxin administration in the present studies produced a progressive elevation of serum triglyceride values. Hypertriglyceridemia was more pronounced in fasted monkeys and was reduced by glucose. Thus differences in triglyceride values reported in the earlier studies of gram-negative sepsis in adults $[9,15]$ and children [16] may relate to the variable use of glucose infusions.

The depression of serum free fatty $\operatorname{acid}(\mathrm{s})$ (FFA) concentrations during endotoxemia (Fig. 1) could be due to either decreased production and/or increased utilization. Hirsh et al. [12] found that, in rabbits given endotoxin, the rise in triglyceride values was preceded by an elevation of FFA which were subsequently incorporated into triglycerides, which suggested increased production. Enhanced utilization of FFA and increased FFA incorporation into triglycerides recently have been reported [7] in monkeys with bacterial infections. Theoretically, FFA release from fat could be stimulated by catecholamines [10] or corticosteroids, both of which are increased during infection and "stress."

The depression of plasma phospholipid concentrations observed in the present study is in agreement with our earlier observation during Salmonella infections in monkeys [6], but the mechanism is obscure. Unchanged plasma cholesterol values after endotoxin (Fig. I) do not preclude the possibility that cholesterol turnover increased; studies in the rhesus monkey during gram-positive and gram-negative infections have documented markedly increased rates of cholesterol turnover [8] with unchanged plasma concentrations.

Thus, the present studies indicate that endotoxin has a marked effect on the pattern of substrate utilization by the host. Although the mechanism(s) for these effects remain unclear, such alterations in substrate utilization may be of great importance during the neonatal period because of the susceptibility of the neonate to gram-negative infections [13]. In addition, the neonate is less able to inactivate endotoxin [1].

\section{Summary}

The effects of experimentally induced endotoxemia on plasma lipids were studied in rhesus monkeys, with the responses in fasted or glucose-infused groups being compared with values obtained in appropriately matched control monkeys. A marked increase in plasma triglyceride concentrations followed endotoxin administration; this change was partially prevented by glucose infusion. A small increase in plasma very low density lipoprotein accompanied the rise in plasma triglycerides. Endotoxin administration also led to depressed free fatty acid and phospholipid values, but plasma cholesterol values remained relatively constant. In comparison to their controls, endotoxemic monkeys showed a delayed clearance of glucose and higher serum insulin values. None of the metabolic changes measured in this study served as an indicator of severity of the endotoxic state or of its outcome. 


\section{References and Notes}

1. Ainbendfr, E., Zepp, H. D., And Hodes, H. L.: Nconatal deficiency in endotoxin inactivation. Pediat. Res., 6: 125 (1972).

2. Asrow, G.: Semiautomated enzymic micro methods for blood glucose and lactic acid on a single filtrate. Anal. Biochem., 28: 130 (1969).

3. Craighead, J. E., and Steinke, J.: Diabetes mellitus-like syndrome in mice infected with encephalomyocarditis virus. Amer. J. Pathol., 63: 119 (1971).

4. Cryer, P. E., Herman, C. M., and Sode, J.: Carbohydrate metabolism in the baboon subjected to gram-negative $(E$. coli) septicemia. I. Hyperglycemia with depressed plasma insulin concentrations. Ann. Surg., 17f: 91 (1971).

5. Farber, E. R., Batsakis, J. G., Giesen, P. C., and Thiessen, M.: Lipoprotein electrophoresis: A comparison of cellulose acetate and paper techniques. Amer. J. Clin. Pathol., 51: 523 (1969).

6. Fiser, R. H., Denniston, J. C., And Bersel, W. R.: Infection with Diplococcus pneumoniae and Salmonella typhimurium in monkeys: Changes in plasma lipids and lipoproteins. J. Infect. Dis., 125: 54 (1972).

7. Fiser, R. H., Denniston, J. C., And Bersel, W. R.: Host fuel interrelationships during infection. Pediat. Res., 6: 398 (1972).

8. Fiser, R. H., Denniston, J. C., Rindsig, R. B., and Beisel, W. R.: Effects of acute infection on cholesterogenesis in the rhesus monkey. Proc. Soc. Exp. Biol. Med., 138: 605 (1972).

9. Gallin, J. I., Kaye, D., and O'Leary, W. M.: Serum lipids in infection. New Engl. J. Med., 281: 1081 (1969).

10. Griffiths, J., Groves, A. C., and Leung, F. Y. T.: The relationship of plasma catecholamines to serum triglycerides in canine gram-negative bacteremia. Surg. Gynecol. Obstet., 134: 795 (1972).

11. Herbert, V., Lau, K. S., Gottlieb, C. W., and Bleicher, S. L.: Coated charcoal immunoassay of insulin. J. Clin. Endocrinol. Metab., 25: 1375 (1965).

12. Hirsh, R. L., McKay, D. G., Travers, R. I., anj) Skraly, R. K.: Hyperlipidemia, fatty liver, and bromsulfophthalein retention in rabbits injected intravenously with bacterial endotoxins. J. Lipid Res., 5: 563 (1964).

13. Krugman, S., ANd Ward, R.: Sepsis in the newborn. In: Infectious Discases of Children, p. 199 (C. B. Mosby Company, St. Louis, 1968).

14. Lefs, R. S., Fiser, R. H., Beisel, W. R., and Barterloni, P.
J.: Effects of an experimental viral infection on plasma lipid and lipoprotein metabolism. Metabolism, 21: 825 (1972).

15. Levin, J., Poore, T. E., Younc, N. S., Margolis, S., Zauber, N. P., ToWNEs, A. S., AND Bel., W. R.: Gram-negative sepsis: Detection of endotoxemia with the Limulus test. Ann. Intern. Med., 76: l (1972).

16. Pollack, J. D., Klainer, A. S., and Cramblett, H. G.: Total serum lipids in infectious disease. Pediat. Res., 6: 387 (1972).

17. Rocha, D. M., Santeusanio, F., Faloona, G. R., and Unger, R. H.: Abnormal pancreatic alpha-cell function in bacterial infections. New Engl. J. Med., 288: 700 (1973).

18. TYTKo, S., Willis, C. E., AND King, J. W.: Semi-automated lipid profile analysis. Automation Anal. Chem., 1: 29 (1967).

19. UNGER, R. H.: Glucagon and the insulin: Glucagon ratio in diabetes and other catabolic illnesses. Diabetes, 21: 324 (1972).

20. Yeunc, C. Y.: Hypoglycemia in neonatal sepsis. J. Pediat., 77: $812(1970)$.

21. Yeung, C. Y., Lee, V. W. Y., and Yeung, M. B.: Glucose disappearance rate in neonatal infection. J. Pediat., 82: 486 (1973).

22. Purina monkcy chow, Ralston Purina Company, St. Louis, Mo.

23. Difco Laboratories, Detroit, Mich.

24. Sigma test kit no. 505, Sigma Chemical Company, St. Louis, Mo.

25. P-1000A pressure transducer, E \& M Instrument Company, Houston, Tex.

26. In conducting the research described in this report, the investigators adhered to the "Guide for Laboratory Animal Facilities and Care," as promulgated by the Committce on the Guide for Laboratory Animal Resources, National Academy of Science-National Research Council. The facilities are fully accredited by the American Association of Accreditation of Laboratory Animal Care.

27. The authors thank Spe-5 T. D. Shultz, Spe-5 R. B. Rindsig, and Ms. Karen Bostian for expert technical assistance and Mrs. Theresa Lane and Mrs. Beverly Fisher for secretarial assistance.

28. Requests for reprints should be addressed to: RoberT $H$. FISER, M.D., Department of Pediatrics, UCLA School of Medicine, Harbor General Hospital, 1000 W. Carson St., Torrance, Calif. 90509 (USA).

29. Accepted for publication August 29, 1973. 